\title{
CARACTERÍSTICAS Y PERSPECTIVAS DE LA TRANSITORIEDAD DEL ARBITRAJE NACIONAL COLOMBIANO COMO MECANISMO ALTERNATIVO DE SOLUCIÓN DE CONFLICTOS A LA LUZ DE LA LEY 1563 DE 2012
}

Berónica Narváez Mercado ${ }^{1}$

Patricia Osorio Coley²

\section{Resumen}

En Colombia el arbitraje data a partir de la Ley 105 de 1890, que facultaba a las personas para someter sus diferencias a la decisión de un árbitro, en ciertos casos pre establecidos por la ley y de acuerdo al procedimiento prescrito para tales situaciones. Los principios espíritu de la Ley 105 de 1890 en lo que concierne al arbitraje, han sido pioneros para legislaciones posteriores en la materia, siendo cimiento para la Ley 103 de 1923 y 105 de 1931, donde se tuvo en cuenta versar sobre el procedimiento para el tratamiento del proceso arbitral. Este investigación se trazó como objetivo general el analizar las características y perspectivas de la Transitoriedad del Arbitraje Nacional como Mecanismo Alternativo de Solución de Conflictos a la Luz de la Ley 1563 de 2012, inicio con la presentación de los antecedentes que enfocan algunas de las características distintivas del arbitraje nacional en Colombia, seguidamente abordo las teorías sobre la naturaleza jurídica del arbitraje, y los conceptos generales que ampliaron la comprensión del lector; de la misma forma se identificaron las características de los preceptos legales, normativos y jurisprudenciales que fijan y definen la transmisibilidad en el

$1 \quad$ Doctorante en Derecho de la Universidad Libre de Colombia. MBA de la Escuela Libre de Derecho de Costa Rica, Abogada, Conciliadora y Docente Investigadora, Directora del Centro de Investigaciones Sociojurídicas de la Facultad de Derecho y Ciencias Políticas de la Corporación Universitaria del Caribe, Líder del Grupo de Investigación GISCER. Email: beronica.narvaez@cecar.edu.co

2 Especialista en Derecho procesal Civil y Abogada de la Corporación Universitaria del Caribe.Email: osorio.patricia@hotmail.com 
arbitramento nacional colombiano, y la prospectiva principal de la ley 1563 de 2012 y su articulación inclusiva de cara a los limitantes materiales, para analizar lo referente a la transitoriedad del Arbitraje Nacional en Colombia. Se logró afirmar que en materia de arbitraje nacional, el nuevo Estatuto no estuvo dirigido a la variación de la normatividad existente, sino a la compilación de esta y al perfeccionamiento de ciertos conceptos y figuras.

Palabras clave: transitoriedad, perspectivas, arbitraje nacional colombiano, mecanismo alternativo de solución de conflictos y la ley 1563 de 2012

\section{Abstract}

In Colombia, arbitration dates back to Law 105 of 1890, which empowered individuals to submit their differences to the decision of an arbitrator, in certain cases pre-established by law and according to the procedure prescribed for such situations. The spirit principles of Law 105 of 1890 regarding arbitration have been pioneers for subsequent legislation on the matter, being the foundation for Law 103 of 1923 and 105 of 1931, where it was taken into account to deal with the procedure for the treatment of the arbitration process. The general objective of this research was to analyze the characteristics and perspectives of the Transition of National Arbitration as an Alternative Dispute Resolution Mechanism in the Light of Law 1563 of 2012, beginning with the presentation of the background that focuses some of the distinctive characteristics of national arbitration in Colombia, followed by the theories on the legal nature of arbitration, and the general concepts that broadened the reader's understanding; In the same way, the characteristics of the legal, normative and jurisprudential precepts that establish and define transmissibility in Colombian national arbitration were identified, as well as the main perspective of Law 1563 of 2012 and its inclusive articulation with respect to material limitations, in order to analyze the transitory nature of National Arbitration in Colombia. It was possible to affirm that in the matter of national arbitration, the new Statute was not directed to the variation of the existing regulations, but to the compilation of these and to the improvement of certain concepts and figures.

Keywords: transience, perspectives, Colombian national arbitration, alternative dispute resolution mechanism and Law 1563 of 2012. 


\section{Introducción}

Hablar del origen del arbitraje para la doctrina es encumbrar hacia la época primitiva, donde las personas estaban llamadas a someter sus diferencias a la decisión de un tercero en razón de carecer de un sistema judicial organizado. Se dice que en Atenas en la antigua Grecia, al surtirse controversias entre personas, la costumbre era concurrir a los tesmotetes, quienes poseían facultades de tribunales de Justicia y por ende conocían de las diferencias y controversias; con fundamento en ello podían exponer soluciones que lograran que las partes llegaran a un acuerdo definitivo. En la Edad Media el arbitraje era el tribunal para solucionar los conflictos entre personas de diversas clases: Señores feudales, comerciantes y artesanos. Todos sometían sus diferencias a este tribunal, o se dirigían directamente al Rey para que decidiera sobre la contienda. Muy a pesar que se fusionaron sistemas como el germano y el romano en la creación de tribunales arbitrales, a finales de la Edad Media el arbitraje se desplomó quedando en desuetud dado que los jueces podían ser árbitros, razón por la que las personas estimaron preferir someter a ellos sus disputas o controversias.

En sus orígenes, cabe destacar que el arbitraje funcionaba de manera ad dohc. El arbitraje en legislaciones como la Ley 103 de 1923 y 105 de 1931, tuvo como fuente el compromiso; la Ley 2 de 1838 autorizo la cláusula compromisoria; la Ley 28 de 1931 instituyó a las Cámaras de Comercio como Tribunal de Comercio para resolver las diferencias que creaban fricción entre comerciantes, en calidad de árbitro o amigable componedor; con posterioridad el Decreto 864 de 1953 concede al Procurador General de la Nación, la potestad de vigilar el funcionamiento de los Tribunales de Arbitramento, condición incluida de forma exacta en el Código de Procedimiento Civil de 1970; con posterioridad el Decreto 2279 de 1989, derogo lo referente al arbitraje del Código de Procedimiento Civil y Código de Comercio, implantando un nuevo procedimiento sobre la materia y las consignas arbitrales; mas sin embargo, la Ley 23 de 1991 recoge y ajusta nuevamente dichas disposiciones sobre arbitraje avistadas en estos dos códigos, derogando así el Decreto 2279 de 1989; con sucesión del Decreto 446 de 1998 que regula todo lo concerniente al procedimiento arbitral; y finalmente se crea la Ley 1563 de 2012, quien recopila de manera ordena todo lo concerniente al arbitraje brindando mayor utilidad de la superación histórica de la administración de justicia de manera privada. 


\section{Teorías sobre la naturaleza jurídica del arbitraje}

Para muchos doctrinantes, la naturaleza jurídica del arbitraje les resulta lo bastante confusa, debido que en su opinión y critica no se consigue claramente ubicar el arbitraje dentro de la división del derecho positivo de forma específica en la rama del derecho público o por contrario en la rama del derecho privado. Atendiendo a esta discusión doctrinal de tipo conceptual sobre la naturaleza jurídica del arbitraje, se presentan las siguientes corrientes:

\section{Teoría Contractualista}

Esta tesis también llamada privatista pura, defiende que el arbitraje gravita en un contrato basado en la voluntad de las partes, que encomiendan el arreglo de sus diferencias a un tercero neutral, llamado árbitro. Otorgando al arbitraje el carácter contractual y, por tanto, privado. Esta teoría contractual, habla entonces de un pacto arbitral (Monroy, C. 1982) que discurre al árbitro como mandatario de las partes, donde el laudo arbitral que dicte no tiene carácter de sentencia, puesto que, aparece como una simple ejecución del mandato por el compromisario.

Los que avalan esta tesis, afirman que los árbitros no realizan funciones propias de administración de justicia, comprendidas entre tales actividades: La aptitud de juzgar y hacer justicia, por ende, el laudo, pese a que se semeje a sentencia, no es su equivalente. (Echeverri, 1999) Dicha teoría surge de la premisa que la función jurisdiccional es considerada como propia de la esencia de la autoridad y el poder estatal, como una de las manifestaciones de los magistrados. (Caivano, 2000).

\section{Teoría Jurisdiccional}

Esta corriente también llamada Tesis Publicista Pura, sostiene que el arbitraje es una institución de esencia procesal, por ende de orden público. Posee carácter de juicio, por ende en esta teoría se contempla que el árbitro cumple con la función de juez y su laudo si se equipara a la sentencia emitida por el juez, Autores como Fenech, Alcalá Zamora, Carreras, Serra y Montes argumentan que la decisión arbitral ostenta todas las notas esenciales de la cosa juzgada, obligatoriedad, ejecutoriedad, imperatividad y que además la excepción procesal para hacerla valer es la de cosa juzgada, además aluden que los árbitros gozan de "autoritas" no de "potestasy por tanto su esencia es de naturaleza jurisdiccional. Bajo este principio, se afianza que la función jurisdiccional otorgada a los Tribunales estatales instituido por ley, 
es ejercida de forma excepcional y temporal por los jueces privados que son los árbitros (Monroy, C. 1982).

\section{Teoría Ecléctica}

La tesis Ecléctica o mixta es defendida por Carnelutti y Prieto Castro. Según Carnelutti el arbitraje es un "equivalente jurisdiccional" ya que a través de él se pueden obtener los mismos objetivos que por la jurisdicción civil. Para la Dra. María de los Ángeles Nahid Cuomo, la teoría mixta o también llamada conciliadora considera el arbitraje como una institución sui generis, de naturaleza mixta o híbrida, en la que conviven, como un todo indisoluble, el origen contractual del mismo y la teología jurisdiccional que explica su aparición, institución contractual por su origen, procesal por sus efectos.

\section{Teoría Autónoma}

El doctrinante peruano Ulises Montoya, plantea la existencia de una nueva teoría denominada Teoría Autónoma que es desarrollada por la francesa Madame Rubellin Deviche, dicha corriente divulga que el arbitraje es autónomo por el uso y su propósito, por lo que no puede ser considerado como contractual, jurisdiccional y menos mixto por no estar de acuerdo con la realidad, pues al arbitraje hay que mirarlo per se, es decir cómo es, en qué consiste, la forma y modo como funciona, las leyes que se han dictado para ayudar y facilitar su desenvolvimiento. (Moreno Baldivieso, 2000)

\section{Arbitraje}

Definición Básica de Arbitraje según el Diccionario Enciclopedia, la definición de arbitraje proporcionada por el Diccionario Jurídico Elemental es: La acción o facultad de arbitrar y el juicio arbitral. Toda decisión dictada por un tercero, con autoridad para ello, en una cuestión o un asunto. Este autor desarrolla el concepto de arbitraje como:

Método extra jurisdiccional de resolución de conflictos que se plantea no sólo en el marco de las relaciones mercantiles o jurídico-civiles, sino también en el tráfico jurídico en masa, mediante la autonomía de la voluntad del as partes, quienes pactan un convenio arbitral. El arbitraje se rige por el sistema monista, es decir, con una regulación común, salvo excepciones. Se caracteriza por el sometimiento de las partes al proceso 
arbitral, así como a la decisión final de los árbitros designados en la forma prevista en la ley.

El arbitraje puede realizarse en equidad o en Derecho: 1) En equidad: basa su fundamento en el leal conocer y entender del individuo que, actuando como árbitro, escuche a las partes, 2) En derecho: este tiene un carácter preferente, salvo acuerdo entre las partes, requiere que el árbitro sea un abogado en ejercicio. La definición de Arbitraje por el Diccionario Terminológico de Arbitraje Nacional e Internacional:

El arbitraje constituye un método de solución extrajudicial de controversias cuyo origen se sitúa en la voluntad de las partes, que, mediante la conclusión de un negocio jurídico denominado «convenio arbitral», confían la solución de un litigio a un tercero imparcial (árbitro) elegido, directa o indirectamente por ellas mismas. El arbitraje, como proceso que es, se basa en el derecho de defensa de las partes y en el principio de igualdad. Las opciones de política jurídica que subyacen a estos preceptos quedan subordinadas siempre a la voluntad de las partes.

El Concepto manejado en Antecedentes judiciales mexicanos, elogiado por Francisco González de Cossio:

El arbitraje es una convención que la ley reconoce y que, por cuanto implica una renuncia al conocimiento de la controversia por la autoridad judicial, tiene una importancia procesal negativa. Ese contrato es el llamado de compromiso, y en virtud de él, las partes confían la decisión de sus conflictos a uno o más particulares; de ese modo, se sustituye el proceso con algo que es a fin a él, en su figura lógica, supuesto que en uno y otro casos, se define una contienda mediante un juicio ajeno; sin embargo, el árbitro no es funcionario del Estado, ni tiene jurisdicción propia o delegada; las facultades de que usa, se derivan de la voluntad de las partes, expresada de acuerdo con la ley, y aunque la sentencia o laudo arbitral, no puede revocarse por la voluntad de uno de los interesados, no es por sí misma ejecutiva." (Semanario Judicial, s.f)

De otro lado Caivano, define el arbitraje como un sistema de resolución de conflictos. Dice que es una herramienta mediante la cual se resuelven los conflictos por particulares que no revisten la calidad de jueces estatales. (Salazar P, 2004). Por su parte Leonardi Herbon, admite el arbitraje como método de solución de controversias mediante 
el cual, en ciertas ocasiones, la ley permite a las partes sustraerse de la intervención de los órganos judiciales estatales. Para Fernando Vidal Ramírez el arbitraje tiene como supuesto un conflicto ínter subjetivo de intereses que resulta de una pretensión a la que se le opone rechazo. Así planteado el conflicto se hace necesario solucionarlo y para esta solución el Estado otorga directamente la tutela jurisdiccional o la delega, a fin de que las mismas partes del conflicto nominen al árbitro o árbitros a los que confieren la facultad de dirimir la controversia. De este modo, el arbitraje se constituye en un medio de solución de conflictos alternativo al Poder Judicial y con características muy propias y diferenciales de otros medios de solución. (Vidal, 2006). Fernando Vidal, concibe el arbitraje como un medio de solución de conflictos alternativo al Poder Judicial, es decir, alternativa a los tribunales ordinarios de justicia. Fernando Rodríguez Mendoza, es contradictorio en ese aspecto, el establece que la figura jurídica del arbitraje no debe concebirse como una alternativa a la justicia ordinaria, porque justicia no hay más que una, sino como un mecanismo que viene a complementarla o incluso a facilitarla.

Finalmente se trae a colación el concepto del tratadista Patricio Aylwin Azocar, quien define el arbitraje como "aquel a que las partes concurren de común acuerdo o por mandato del legislador y que se verifica ante tribunales especiales, distintos de los establecidos permanentemente por el Estado, elegidos por los propios interesados o por la autoridad judicial en subsidio, o por un tercero en determinadas ocasiones." (Monroy Cabra, 1982)

\section{El arbitraje como método heterocompositivo para la resolución de los conflictos}

Permite que las partes en contienda faculten a un árbitro o tribunal la autoridad de resolver la controversia, mediante el pronunciamiento de una decisión denominada laudo arbitral. Para la doctrina en cuestión de resolución de conflictos reconoce dos grandes sistemas de respuesta, el de autocomposición y el heterocomposición, este último está compuesto por aquellos medios en los cuales las partes enfrentadas someten la solución de sus conflictos a terceros que se encargan de resolverlos independientemente de la autonomía de la voluntad de las partes.

El Artículo $1^{\circ}$ de la ley 1563 de 2012, define el arbitraje como:

El arbitraje es un mecanismo alternativo de solución de conflictos mediante el cual las partes defieren a árbitros la solución de una controversia relativa a asuntos de libre 
disposición o aquellos que la ley autorice. El arbitraje se rige por los principios y reglas de imparcialidad, idoneidad, celeridad, igualdad, oralidad, publicidad y contradicción. El laudo arbitral es la sentencia que profiere el tribunal de arbitraje. El laudo puede ser en derecho, en equidad o técnico. En los tribunales en que intervenga una entidad pública o quien desempeñe funciones administrativas, si las controversias han surgido por causa o con ocasión de la celebración, desarrollo, ejecución, interpretación, terminación y liquidación de contratos estatales, incluyendo las consecuencias económicas de los actos administrativos expedidos en ejercicio de facultades excepcionales, el laudo deberá proferirse en derecho. La jurisprudencia ha determinado conforme a la Constitución política, que el arbitramento es un mecanismo jurídico en virtud del cual las partes en conflicto deciden someter sus diferencias a la decisión de un tercero, aceptando anticipadamente sujetarse a lo que allí se adopte. (Sentencia C-242 de 1997).

La Constitución política de Colombia de 1991, en su artículo 116 (inciso 4), determina quienes ejercen funciones de administración de justicia:

Los particulares pueden ser investidos transitoriamente de la función de administrar justicia en la condición de jurados en las causas criminales, conciliadores o en la de árbitros habilitados por las partes para proferir fallos en derecho o en equidad, en los términos que determine la ley.

De acuerdo a lo descrito, los particulares pueden ser investidos transitoriamente de la calidad árbitros habilitados por las partes, en asuntos susceptibles de transacción, de conformidad con los procedimientos señalados en la ley. El artículo 116 de la Constitución Política junto con la Ley 446 de 1998, desarrolla la figura del arbitramento, entendido como un mecanismo alternativo de solución de controversias mediante el cual las partes involucradas resuelven voluntaria y libremente sustraer de la justicia estatal la solución de un conflicto, a fin de que un tercero particular, revestido temporalmente de función jurisdiccional, adopte una decisión de carácter definitivo y vinculante para las partes. Los árbitros se pronuncian sobre los hechos que dieron lugar a la controversia, resuelven las pretensiones de las partes, practican y valoran las pruebas, resuelven el litigio con fundamento en 
los mandatos constitucionales y legales o atendiendo a los principios de equidad, y sus decisiones hacen tránsito a cosa juzgada. Por estas razones, la jurisprudencia constitucional ha considerado que la decisión arbitral es eminentemente jurisdiccional y equivale a una providencia judicial. Cabe anotar, tal como lo ha sostenido la Corte, que: además, estos mecanismos alternativos de resolución de conflictos encuentran base constitucional no sólo en su reconocimiento expreso en el artículo 116 superior sino también en otros principios y valores constitucionales.

\section{Evolución de los Fundamentos Normativos del Arbitramento}

Se dice que el arbitraje en Colombia tiene su alba en la Ley 105 de 1890, donde se facultaba a los árbitros para conocer de controversias que surgieran entre personas capaces de transigir, en los casos que se encontrare permitida la transacción y de acuerdo a lo señalado para su procedimiento en la Ley. Pero, más allá de la influencia colonial, y las consignas desarrolladas dentro de esta ley, se citará el tránsito evolutivo, iniciando con el Decreto 2279 de 1989, la ley 23 de 1.991, el Decreto 2651 de 1.991, la ley 270 de 1.996, la ley 446 de 1.998, el Decreto 1818 de 1998 y la Ley 1563 de 2012.

\section{Jurisprudencia que fija y define la Transigibilidad en el Arbitramento Nacional colombiano}

Seguidamente de la evolución normativa señalada, se busca hacer una breve reconstrucción de algunos pronunciamientos de la Corte Constitucional frente al carácter de transigibilidad en el arbitramento colombiano. Sentencia C-060 de 2001, fundamento 3:

El arbitraje es un mecanismo que tiene ciertas características básicas: (i) es uno de los instrumentos autorizados para que los administrados puedan administrar justicia; (ii) está regido por el principio de habilitación o voluntariedad, pues el desplazamiento de la justicia estatal por el arbitramento tiene como fundamento "un acuerdo previo de carácter voluntario y libre efectuado por los contratantes". "(iii) Además el arbitramento es temporal, pues la competencia de los árbitros está restringida a lo que los árbitros plantean. (iv) Es también de naturaleza excepcional pues la constitución impone límites materiales a la figura, "de suerte que no todo problema jurídico puede ser objeto de laudo" ya que es claro que existen bienes jurídicos cuya disposición no puede dejarse al arbitrio de un 
particular, así haya sido voluntariamente designado por las partes enfrentadas.

Con base a esa naturaleza excepcional, se hace posible hablar del carácter transigible del arbitramento. Sentencia C-226 de 1993: Por regla general se puede transigir sobre todo aquello que se puede disponer (...) El arbitramento debe referirse a bienes o derechos patrimoniales de que puedan disponer las partes libremente... (Sentencia C-226 de 1993). El Código civil, habla de la capacidad de transigir, haciendo referencia en la exigencia de que quien acuda a los medios de resolución alterna debe tener la capacidad plena, de disposición sobre los bienes jurídicos objeto de litigio, que además deben recaer sobre materias transigibles. (Código Civil Colombiano, art.2470). La Sentencia C-098 de 2001

Se ha entendido que la justicia arbitral sólo puede operar cuando los derechos en conflicto son de libre disposición por su titular, es decir, que frente a ellos exista la libertad de renuncia en un todo o en parte. Esta capacidad de renuncia o de disposición, es lo que determina el carácter de transigible de un derecho o de un litigio. Esta libertad de renuncia está determinada por la naturaleza misma del derecho y corresponde al legislador establecer en qué casos ésta es posible - capacidad legal de disposición -." "Así, frente a ciertos derechos o bienes, el legislador podría optar por permitir su disponibilidad $y$, en esa medida, los conflictos que de ellos se susciten someterlos a la decisión de un árbitro, si esa es la voluntad de las partes.

La Sentencia T-017 de 2005: Necesaria transigibilidad del objeto litigioso: pretensiones de "contenido económico y carácter patrimonial" (Sentencia T-017 de 2005) y"La justicia arbitral solo puede decidir sobre aquellos asuntos susceptibles de transacción que surjan entre personas capaces de transigir" (Consejo de Estado, Sala de lo Contencioso Administrativo, Sección Tercera, Sentencia de junio 08 de 2000, Exp. 16973).

La Sentencia T-288 de 2013, de acuerdo con la jurisprudencia de la Corte Constitucional, una providencia judicial adolece de un defecto orgánico cuando el funcionario judicial que la profirió carece absolutamente de competencia para resolver el asunto. En materia arbitral el defecto orgánico adquiere unas características especiales, ya que la conformación de un tribunal de arbitramento es de carácter temporal, por lo que está sujeta a la resolución de determinadas materias 
y depende de la voluntad de las partes. En este punto es importante tener en cuenta el principio kompetenz-kompetenz, en virtud del cual los tribunales de arbitramento tienen un margen autónomo de interpretación para determinar el alcance de su propia competencia, de modo que incurrirán en un defecto orgánico solamente cuando han "obrado manifiestamente por fuera del ámbito definido por las partes, o excediendo las limitaciones establecidas en el pacto arbitral que le dio origen, o en la Constitución y la ley, al pronunciarse sobre materias no transigibles.El principio kompetenz- kompetenz (El mencionado principio se traduce de la doctrina alemana como Principio de la competencia-competencia) goza de reconocimiento uniforme a nivel del derecho comparado, pues ha sido consagrado en numerosas legislaciones nacionales, en convenciones internacionales que regulan temas de arbitramento, en las reglas de los principales centros de arbitraje internacional y en la doctrina especializada en la materia, así como en decisiones judiciales adoptadas por tribunales internacionales.

Evidentemente y tal como lo sostiene la Corte en la Sentencia C-330 de 2012: El arbitramento es excepcional.

La habilitación de particulares para solucionar conflictos por medio del arbitramento cuenta también con claras limitaciones materiales, pues no todo problema jurídico puede ser objeto de un laudo. El legislador ha sido consciente de que la equiparación funcional que se hace entre los funcionarios del Estado y ciertos ciudadanos, temporalmente investidos de poder jurisdiccional, no puede extenderse a todas las materias, pues es claro que existen bienes jurídicos cuya disposición no puede dejarse al arbitrio de un particular, así haya sido voluntariamente designado por las partes enfrentadas.

Principios como el de la seguridad jurídica hacen necesario que ciertos asuntos sean ventilados a través de la jurisdicción ordinaria, pues se trata de eventos que se relacionan con la garantía de derechos constitucionales fundamentales, con el reconocimiento de facultades legalmente reconocidas a favor de ciertos ciudadanos -v.g. derechos mínimos de los trabajadores-, o con el ejercicio del control estatal sobre ciertas circunstancias jurídicamente relevantes como "la fijación del estado civil, las cuestiones que tengan que ver con derechos de incapaces o derechos sobre los cuales la ley prohíbe a su titular disponer. La Sentencia C-060 de 2001 en Relación a la Transigibilidad indica: 
La colaboración prestada por los particulares en la administración de Justicia tiene un claro fundamento en la Constitución, sin embargo dicha colaboración, en el ámbito jurisdiccional, tiene carácter transitorio y excepcional. En primer término, el arbitraje solo puede tener por objeto asuntos que por su naturaleza sean susceptibles de dicho trámite, y es evidente que no todos los son. No todo asunto de competencia de los jueces ordinarios, en consecuencia puede ser trasladado a la Justicia arbitral." (Sentencia T-057 de 1995)

De acuerdo con la Sentencia C-060 de 2001, no se considera de carácter transigible: El Estado civil de las personas, que está constituido por un conjunto de situaciones jurídicas que relacionan a cada persona con la familia de donde proviene, o con la familia que ha formado, y con ciertos hechos fundamentales de la misma personalidad. En relación con la familia de donde proviene una persona, se puede afirmar de ella si es hijo legítimo o extramatrimonial; respecto a la familia que forma, puede afirmarse si es casado o soltero; y en relación con ciertos hechos fundamentales de la personalidad de cada ser humano, podemos decir si es varón o mujer (sexo), si es mayor o menor de edad, si vive aún o ha muerto, ni los Derechos Fundamentales que son aquellos Derechos inherentes a la persona humanos, ni los derechos de los incapaces. Se ha entendido que la justicia arbitral sólo puede operar cuando los derechos en conflicto son de libre disposición por su titular, es decir, que frente a ellos exista la libertad de renuncia en un todo o en parte. Esta capacidad de renuncia o de disposición, es lo que determina el carácter de transigible de un derecho o de un litigio. Dicha libertad de renuncia está determinada por la naturaleza misma del derecho.

\section{Prospectiva de la ley 1563 de 2012 y su articulación inclusiva de cara a los limitantes materiales}

Con la entrada en vigencia de la ley 1563 de 2012, se logra una transición de la justicia publica a la justicia privada, el arbitraje nace entonces como la posibilidad a través de la cual los particulares consiguen administrar justicia, dado, que se les confiere la atribución de resolver conflictos jurídicos, previo acuerdo de voluntades entre las personas que discuten en derecho. Piso jurídico atribuible al artículo 116, inciso 4to de la Constitución política, dado que brinda las herramientas jurídicas a través de las cuales los ciudadanos son investidos de la función de impartir justicia 
de manera ocasional en calidad de conciliadores o árbitros. La colaboración prestada por los particulares en la administración de Justicia tiene claro fundamento en la Constitución.

Hablar de Autonomía de la libertad, es la oportunidad de escogencia entre la Justicia Permanente o la Transitoria, y, por regla general también se puede escoger la calidad del arbitramento: Derecho, equidad o técnico, no pudiendo además ser de consagración forzosa lo que la diferencia de la institución de la conciliación.

La nota característica de este instituto, requisito de la propia Constitución impone y que la jurisprudencia constitucional ha resaltado, está en que los sujetos en controversia o que prevean que pueden llegar a estarlo, determinen autónoma y voluntariamente que su diferencia no será decidida por el Estado a través de sus jueces, si no por un particular a quien ellos le reconocen el poder y la competencia para resolver sus desavenencias-poder habilitante de las partes-.

Es, en este contexto, en donde el arbitramento adquiere su condición de mecanismo alternativo de resolución de conflictos, pues son las partes las que voluntariamente y sin apremio alguno, deciden no hacer uso del aparato de justicia estatal, a la luz de su evaluación autónoma de las circunstancias que hacen conveniente recurrir a tal curso de acción, y no de una imposición que afecte su libertad negocial". (Sentencia C-060 de 2001). Carácter Transigible: “...Por regla general se puede transigir sobre todo aquello que se puede disponer (...) El arbitramento debe referirse a bienes o derechos patrimoniales de que puedan disponer las partes libremente..." (Sentencia C-226 de 1993). La Solución Está en Manos del Árbitro o Tribunal (Según el caso): Se diferencia técnicamente de la conciliación, ya que en la misma la solución proviene de las partes con intervención de un neutral que las oriente, contrarios sensu, en el arbitramento la solución es tomada por el árbitro o tribunal. EL Fallo Adoptará la Denominación de Laudo: Bajo éste entendido, empero se puede apreciar que el laudo al ser una expresión de la actividad judicial pude y debe elevarse a la calidad de aquella providencia judicial de fondo; es decir la sentencia....". (Consejo de Estado. Sección Tercera. Diciembre de 2005). Por otro lado, en razón de que los árbitros -como los jueces ordinarios- deben (i) cumplir con términos perentorios y (ii) que sus pronunciamientos están sometidos a la revisión eventual por parte de otras autoridades además de contar con el poder vinculante de cualquier sentencia." (Sentencia C- 060 de 2001). Por lo tanto, el laudo no pude ir en contra del ordenamiento jurídico y 
es susceptible de control de legalidad y de constitucionalidad. Debiendo señalar que es posible tutelar por vías de hecho un laudo arbitral, el ciudadano puede recurrir a la acción de Tutela, invocando la existencia de una vía de hecho, con el objeto de restituir la integridad de los derechos Fundamentales vulnerados. De Aplicación Excepcional: La habilitación de particulares para solucionar conflictos por medio del arbitramento cuenta también con claras limitaciones materiales, pues no todo problema jurídico puede ser objeto de un laudo.

El legislador ha sido consciente de que la equiparación funcional que se hace entre los funcionarios del Estado y ciertos ciudadanos, temporalmente investidos de poder jurisdiccional, no puede extenderse a todas las materias, pues es claro que existen bienes jurídicos cuya disposición no puede dejarse al arbitrio de un particular, así haya sido voluntariamente designado por las partes enfrentadas.

Principios como el de la seguridad jurídica hacen necesario que ciertos asuntos sean ventilados a través de la jurisdicción ordinaria, pues se trata de eventos que se relacionan con la garantía de derechos constitucionales fundamentales, con el reconocimiento de facultades legalmente reconocidas a favor de ciertos ciudadanos -v.g. derechos fundamentales de los contratantes, o con el ejercicio del control estatal sobre ciertas circunstancias jurídicamente relevantes como "la fijación del estado civil, las cuestiones que tengan que ver con derechos de incapaces o derechos sobre los cuales la ley prohíbe a su titular disponer (Sentencia C-060 de 2001). El arbitramento es de carácter temporal, el proceso arbitral, está investido del poder de administrar justicia, habilitado por las partes, pero no por ello las atribuciones judiciales conferidas pueden tornarse de manera indefinida, dada que su naturaleza se deriva de una jurisdicción meramente transitoria y excepcional. (Sentencia T 057 de 1995). Es una Institución de Orden Procesal: Lo cual significa que el arbitramento, "garantiza los derechos de las partes enfrentadas disponiendo de una serie de etapas y oportunidades para la discusión de los argumentos, la valoración de las pruebas aportadas y, aun, la propia revisión de los pronunciamientos hechos por los árbitros" (Sentencia C-330 de 2000).

\section{Clasificación del Arbitraje según el fallo}

En Derecho, se dice que si las partes no determinan el tipo de arbitraje será en Derecho, es aquel en el cual los árbitros fundamentan su decisión en el derecho positivo vigente; la nueva Ley estableció que, 
cuando una parte es entidad pública o ejerce funciones administrativas el laudo debe proferirse en derecho. En Conciencia o Equidad: es aquel en que los árbitros deciden según el sentido común y la equidad y Técnico: Este arbitraje dentro de la nueva ley de arbitramento, es concebido como un mecanismo al que las partes pueden acudir sin tener que hacerlo en un centro de arbitraje. El artículo primero, de la ley en estudio, trajo consigo una variación significativa en relación a lo contemplado en la normatividad anterior, al determinar que la existencia de la decisión arbitral o laudo, puede ser en derecho, en equidad o técnico y no el arbitraje como tal

\section{Clases de Arbitraje Según el tribunal que lleve a cabo el Procedimiento Aplicable dentro del proceso arbitral}

El Arbitraje Ad Hoc: Aquel en que las partes acuerdan autónomamente las reglas del procedimiento aplicables en la solución de su conflicto. El Arbitraje Institucional: Aquel en que las partes se someten a un procedimiento establecido por el centro de arbitraje y El Arbitraje Legal: Aquél cuando a falta de dicho acuerdo el arbitraje se realice conforme a las disposiciones legales vigentes. Con la Ley 1563 de 2012, a través de su artículo 2, se definió la distinción sobre las Clases de arbitraje. En primer lugar, se señaló el arbitraje ad hoc, textualmente como lo expresa el contenido del artículo, es el conducido directamente por los árbitros, y en segundo lugar, se señaló, el arbitraje institucional que es el administrado por un centro de arbitraje. De la misma manera, continuó abierto a resaltar, que a falta de acuerdo respecto de su naturaleza y cuando en el pacto arbitral las partes guardaren silencio, el arbitraje será institucional. El arbitraje institucional será entonces, aquel que se despliega conforme al reglamento establecido por un centro de arbitraje, mientras que el arbitraje ad hoc o independiente es aquel en el cual las partes resuelven el conflicto conforme a las normas por ellas mismas acordadas, sin la presencia de un reglamento de un centro de arbitraje.

Después de la ley 446 del 98 existían tres clases de arbitraje, el legal cuyo procedimiento era el previsto en la ley, el institucional cuyo procedimiento era el previsto por los centros de arbitraje y el arbitraje independiente cuyo procedimiento era el regulado por las partes con infinidad de limitaciones de las decisiones de la Corte Constitucional frente a la materia, es decir, que esta clasificación existía y dependía del tipo del procedimiento; la nueva ley, 1563 de 2012, lo que dice es que las clases de arbitraje ya no dependen de la fuente y tipo de procedimiento, ahora lo que va a determinar las clases de arbitraje es si se acude o no a 
un centro de arbitraje. Adicionándose que cuando la controversia verse sobre contratos celebrados por una entidad pública o quien desempeñe funciones administrativas, el proceso se regirá por las reglas señaladas en la misma ley para el arbitraje institucional.

El proceso arbitral institucional, se extiende al artículo 58 de la ley en estudio, visibilizando, reglas de procedimiento, en miras a que los arbitrajes en que no sea parte el Estado o alguna de sus entidades, los particulares podrán acordar las reglas de procedimiento a seguir, directamente o por referencia a las de un centro de arbitraje, respetando, en todo caso los principios constitucionales que integran el debido proceso, el derecho de defensa, y la igualdad de las partes. El legislador quiso quitarles el monopolio de los procesos arbitrales a los centros de arbitraje, para que hubiese procesos de arbitraje de árbitros particulares.

Cuando la Constitución defiere a los particulares la función de administrar justicia en calidad de árbitros, les confía, como a todos los demás jueces, la solución de contenciones jurídicas entre las partes en concordancia con la Constitución y las leyes. De ahí que la institución arbitral en nuestro ordenamiento tenga el carácter de un proceso, que garantiza los derechos de las partes enfrentadas disponiendo una serie de etapas y oportunidades para la discusión de los argumentos, la valoración de las pruebas aportadas, y, aún, la propia revisión de los pronunciamientos hechos por los árbitros (Corte Constitucional, 2000)

Dentro de los presupuestos básicos de la efectividad y ventajas que desarrolló la estructuración y expedición de la ley 1563 de 2012, se encuentra que la Celeridad en la resolución de conflictos; dado que los Tribunales son conformados para resolver un sólo conflicto, y se les concede un plazo determinado para concluir las etapas y obtener una decisión, reduce los costos de transacción asociados a los tiempos excesivamente largos de las decisiones de la justicia permanentes, las partes se hallan facultadas para seleccionar o escoger su propio juez, esta es una clara ventaja, dado que concibe una mayor confiabilidad en quienes dirimen el conflicto, puesto que han sido las mismas partes quienes decidieron su elección frente a los árbitros en razón de su formación o experiencia, lo que conllevaría a un mayor respeto y mejor ánimo de acatar la decisión impartida, la decisión del tribunal arbitral laudo puede ser más acertada que la decisión de una autoridad judicial como lo es la sentencia, debido a que las partes pueden elegir a los árbitros, lo que permite que estas elijan personas expertas en la materia; con dominio y conocimiento del tema objeto de la controversia, una 
mayor seguridad jurídica, con relación a la tendencia del respeto por el "precedente arbitral" por parte de cada uno de los centros de arbitraje, mientras que en la justicia permanente el precedente solo es aceptado en la jurisdicción constitucional a nivel de doctrina constitucional, la confidencialidad del proceso arbitral, en razón a que el conflicto se resuelve de manera privada, "representa un indudable aspecto positivo, especialmente para sujetos que no pretenden divulgar noticias sobre sus asuntos económicos". (Tarufo, 2008), el proceso arbitral goza de una plena inmediación, debido a que los árbitros conocen de cerca a las partes, el conflicto como tal, y practican personal y de manera conjunta las pruebas, actos estos, que facilitan que se tenga una mayor apreciación directa de ellas.

La vinculación de los garantes no signatarios del pacto en especial, a las compañías de seguros al proceso arbitral, con el fin de evitar que las reclamaciones frente a ellos se tuvieran que resolver en un proceso distinto. Es decir que se da el llamamiento en garantía, tal como lo establece el Parágrafo lro del artículo 37 de la ley de arbitraje, donde se permite la intervención de terceros en llamamiento en garantía de un contrato que tiene pacto arbitral, quedando vinculado a los efectos del mismo, el trámite de la anulación de la decisión o laudo arbitral es mucho más expedito, más rápido, las causales son mucho más aterrizadas a la realidad actual, y en cuanto a los efectos que puede tener la anulación también es positivo. Cabe destacar la compilación ordenada y elocuente frente a las disposiciones relativas a la materia de arbitraje, con secuencia lógica y esquemática; poniéndose en valor el aporte conceptual que facilita el manejo y estudio de la normatividad. Existe una garantía constitucional de acceso a la Justicia en Colombia, pero no connota esto que globalizadamente todas las disputas entre particulares deban en todo caso ser resueltas por los jueces. Tal como se ha esbozado en párrafos anteriores, el artículo 116 de la Constitución política de Colombia, garantiza la existencia de Mecanismos Alternativos de Solución de Conflictos, como la conciliación o el Arbitraje, los cuales pueden ser ampliados por el legislador, constituyéndose así en una vía útil, en ciertos casos, para descongestionar la administración de justicia.

Es relevante señalar que la Carta política establece un régimen democrático participativo, que propicia la colaboración de los particulares en la administración de justicia y en la resolución de sus propios conflictos. Y es aquí donde surge un claro interrogante para la Corte: ¿Hasta qué punto puede la Ley 
obligar a una persona a renunciar acceder a la administración de justicia a fin que se resuelva su litigio por un mecanismo alternativo? Frente a tal interrogante la Corte responde:

Se hace necesario armonizar, con base en los principios constitucionales, los mandatos contenidos en el artículo 116 de la Carta, que prevé los mecanismos alternativos, y el artículo 229, que garantiza a toda persona el derecho a acceder a la administración de justicia. Así las cosas y teniendo en cuenta que Colombia es una Democracia Participativa, bien puede la Ley favorecer que sean las propias personas quienes soluciones directamente sus problemas, por ejemplo estableciendo que estas deben intentar previamente la conciliación de sus diferencias antes de acudir a los jueces.

En efecto, si esa instancia consensual permite que las partes acuerden una solución satisfactoria para su litigio, en nada se ha vulnerado el derecho a acceder a la justicia ya que las personas han accedido a una solución justa para su controversia. Sin embargo, en la medida en que toda persona tiene derecho a acceder a la administración de justicia, estos estímulos legales al uso de los mecanismos alternativos de solución de conflictos no pueden llegar al extremo de bloquear o afectar de manera desproporcionada la posibilidad de una persona de llevar su controversia ante los jueces. Así, como en la Carta Política nada se opone a que la ley consagre como requisito de procedibilidad, para que se pueda demandar judicialmente en ciertos ámbitos el que la persona haya intentado la conciliación previamente, sin embargo esa exigencia puede tornarse inconstitucional en determinados casos, si llega a implicar un obstáculo extremadamente gravoso para el individuo lleve su caso ante los jueces. Eso puede suceder por ejemplo: Si se obliga a la persona a intentar previamente la conciliación, pero sin que la ley prevea la interrupción de los términos de caducidad cuando la persona acude a la instancia conciliadora, ya que si los términos de caducidad son cortos, de esa manera de impedir el acceso a Justicia, con lo cual se estaría trasgrediendo el artículo 229 de la Constitución." (Sentencia C-242 de 1997). De otro lado, la Figura del Arbitramento, contribuye a la descongestión, eficacia, celeridad y efectividad, del aparato estatal de administración de Justicia, sino en que proporciona a los ciudadanos una opción voluntaria de tomar parte activa en la resolución de conflicto. (Sentencia C-098 de 2001). 
El arbitramento debe aceptarse y entendenderse como una institución al que el constituyente le reconoció una función fundamental dentro la administración de Justicia, pues son mecanismos a los que se puede recurrir opcionalmente para poner fin a las controversias, sin intervención directa del Estado, lo que permite no solo la descongestión del aparato de Justicia si no la participación activa de los particulares en definición de los conflictos, materializando así el régimen democrático participativo que diseño el constituyente. En este orden de ideas, es perfectamente posible que el legislador estimule la resolución de conflictos, directamente por los propios afectados, por medio de figuras como la conciliación o la amigable composición, o por terceros que no sean jueces, como sucede en el caso de los árbitros o de ciertas autoridades administrativas y comunitarias." (Sentencia C-163 de 1999). Se tiene que excepcionalmente las autoridades administrativas pueden ser investidas legalmente de la función de administrar justica en las materias específicamente previstas en la Ley, siempre y cuando esta habilitación no implique la instrucción de sumarios y el juzgamiento de delitos. Razón por la cual a los particulares le queda totalmente vedado a los particulares ejercer justicia en calidad diferente a la de conciliador o árbitro; tal como lo ha reconocido la Corte Constitucional en su jurisprudencia, esta facultad es esencialmente ocasional o transitoria.

\section{Conclusiones}

Se ha logrado analizar que el arbitraje es un mecanismo alternativo de solución de conflictos de carácter transitorio. El sustento de la justicia arbitral es el reconocimiento expreso de la decisión libre y voluntaria de las partes contratantes de no acudir al sistema estatal de administración de justicia. El Arbitraje es un mecanismo de carácter temporal o transitorio, excepcional, voluntario, una institución de orden procesal, goza del principio de voluntariedad, es una figura procesal, y un verdadero procedimiento judicial en sentido material y tiene un carácter consensual, esto es, se basa en la cultura del acuerdo, al tratar de impedir la confrontación directa entre los interesados y la ruptura, sin duda traumática, del negocio. Al escoger 
el arbitraje, las partes optan por un procedimiento privado de solución de controversias en lugar de acudir ante los tribunales ordinarios.

Existe un debate doctrinal en torno a la naturaleza del arbitraje, que ha dado lugar al surgimiento de diferentes teorías: a) las denominadas Contractualista o privatistas, que ponen el acento en el acuerdo de voluntades que da origen al convenio arbitral, como manifestación de autonomía de la voluntad, equiparable a lo que sucede en cualquier contrato; b) las jurisdiccionalista o procesalistas que asimilan las funciones de los árbitros a las del órgano judicial, sobre todo, basándose en los paralelismos en cuanto a los efectos que producen los laudos arbitrales con respecto a las sentencias jurisdiccionales; las intermedias o sincréticas, que mezclan las dos anteriores. El arbitraje como mecanismos alternativo de solución de conflictos no sustituye el sistema jurisdiccional pero si lo complementa. Las alternativas privadas para la solución de conflictos no deben ser impuestas unilateralmente por el estado con el objeto de dar solución a problemas estructurales que apremian a la administración de la justicia.

\section{Referencias}

Benetti Salgar, Julio (1994). El Arbitraje en el Derecho Colombiano. Temis, Bogotá.

Cavaino J. Roque (2000). Arbitraje, Editorial Ad Hoc, Segunda edición, Buenos Aires, pp.915.

Collantes González, Jorge Luis. (2007). Palestra Editores-Estudio, Segunda Parte, Freyre. Lima, pp. 317-319.

Consejo de Estado, Sala de lo Contencioso Administrativo, Sección Tercera, Sentencia de junio 08 de 2000, Exp. 16973

Constitución Política de Colombia [Const]. Art. 2-116-229, entre otros. Julio 7 de 1991 (Colombia).

Corte Constitucional de Colombia. Sentencia C-226 de 1993. (M.P. Alejandro Martínez Caballero: Junio 17 de 1993).

Corte Constitucional de Colombia. Sentencia C-247 de 1994. (M.P. Alfredo Beltrán Sierra: abril 21 de 1994).

Corte Constitucional de Colombia. Sentencia T 057 de 1995. (M.P. Eduardo Cifuentes Muñoz: Febrero 20 de 1995). 
Corte Constitucional de Colombia. Sentencia C-294 de 1995. M.P. Eduardo Cifuentes Muñoz: Julio 26 de 1995).

Corte Constitucional de Colombia. Sentencia C 242 de 1997. (M.P. Hernando Herrera Vergara: Mayo 20 de 1997).

Corte Constituciona de Colombia. Sentencia C-163 de 1999. (M.P. Alejandro Martínez caballero: Marzo 7 de 1999).

Corte Constitucional de Colombia. Sentencia C 672 de 1999. (M.P. Eduardo Cifuentes Muñoz: Septiembre 9 de 1999)

Corte Constitucional de Colombia. Sentencia 330 de 2000. (M.P. Carlos Gaviria Díaz: Marzo 22 de 2000)

Corte Constitucional de Colombia. Sentencia C-060 de 2001. (M.P. Carlos Gaviria Díaz: Enero 24 de 2001)

Corte Constitucional de Colombia. Sentencia C-098 de 2001(Martha Sachica Mendez: Enero 31 de 2001)

Corte Constitucional de Colombia. Sentencia T-121 de 2002, (M.P. Jaime Cordoba Triviño: Febrero 22 de 2002)

Corte Constitucional de Colombia. Sentencia C-1038 de 2002. (M.P. Eduardo Montealegre Lynett: Noviembre 28 de 2002)

Corte Constitucional de Colombia. Sentencia T-017 de 2005. (M.P. Rodrigo Escobar Gil: Enero 20 de 2005).

Corte Constitucional de Colombia. Sentencia C- 961 de 2006. (Rodrigo Escobar Gil: Noviembre 22 de 2006).

Corte Constitucional de Colombia. Sentencia T-790 de 2010. (M.P. Jorge Ignacio Pretelt: Octubre 1 de 2010).

Corte Constitucional de Colombia. Sentencia C-330 de 2012. (M.P. Humberto Sierra Porto: Mayo 9 de 2012).

Corte Constitucional de Colombia. Sentencia T-288 de 2013. (M.P. Jorge Pretelt Chajub: Mayo 20 de 2013).

Cuomo, Maria de los Ángeles (2005). Apuntes de Derecho Internacional Privado, de la Universidad Privada de Santa Cruz de la Sierra (U.P.S.A.), Santa Cruz-Bolivia.

Decreto 864 de 1953. 
Decreto 2279 de 1989. Por el cual se implementan sistemas de solución de conflictos entre particulares y se dictan otras disposiciones. Octubre 7 de 1989. Diario Oficial No. 39.012.

Decreto 2651 de 1.991. Por el cual se expiden normas transitorias para Descongestionar los Despachos Judiciales. 25 de Noviembre de 1991. Diario Oficial 40177.

Decreto 1818 de 1998. Por medio del cual se expide el Estatuto de los mecanismos alternativos de solución de conflictos. Septiembre 7 de 1998. Diario Oficial 43380.

Escudero Álzate, María Cristina (2013). Mecanismos alternativos de solución de conflictos. Leyer.

González de Cossio, Francisco.

Gil Echeverri, Jorge Hernan (1999). Citando a Chiovenda y Betti, en el Nuevo Régimen de Arbitramento, Editorial Cámara de Comercio de Bogota, Bogota, pp. 24

Hinojosa Segovia, R (2006). Sistemas de solución extrajurisdiccional de conflictos. Madrid: Centro de Estudios Ramón Areces.

Ley 105 de 1890. Por la cual se dictan normas sobre la Cámara de Comercio. Febrero 23 de 1931. Diario Oficial No. 21.624.

Ley 103 de 1923. Sobre Organización Judicial y Procedimiento Civil. Diciembre 5 1924. Diario Oficial No. 19498 a 19509.

Ley 105 de 1931. Sobre la organización judicial y procedimiento civil. Octubre 24. Diario Oficial No 1.823.

Ley 28 de 1931. Sobre Cámaras de Comercio. Febrero 23 de 1931. Diario Oficial No. 21.624.

Ley 23 de 1.991. Por medio de la cual se crean mecanismos para descongestionar los Despachos Judiciales, y se dictan otras disposiciones. Marzo 21 de 1991. Diario Oficial 39752.

Ley 270 de 1.996. Estatutaria de la Administración de Justicia. Marzo 15 de 1996. Diario Oficial 42745.

Ley 446 de 1.998. Se adoptan normas del decreto 2651 de 1991.Julio 8 de 1998.Diario Oficial 43335. 
Ley 1563 de 2012. Por medio de la cual se expide el Estatuto de Arbitraje Nacional e Internacional y se dictan otras disposiciones. Julio 12 de 2012. Diario Oficial No. 48.489.

López Blanco, Hernan (1999). Instituciones del Derecho Procesal Civil Colombiano, Dupre Editores, Bogotá, pp 795-796.

Lorca Navarrete, Antonio María (1989). Derecho de Arbitraje Interno e Internacional, Editorial Techno, Madrid-España.

Monroy, Cabra, Marco Gerardo (1982). Arbitraje Comercial, Editorial Temis, Bogota-Colombia, pp. 3-6-7

Moreno Baldivieso, Ramiro (2000), El Arbitraje Comercial en Bolivia, La Paz-Bolivia, pp. 12

Oppettit, B. (2006). Teoría del Arbitraje. Traducido por Eduardo Silva Romero, Fabricio Mantilla Espinoza y José Joaquín Caicedo Demoulin. Legis Editores, Bogotá.

Quintero, Beatriz \& Prieto, Eugenio (2000). Teoría General del Proceso. Temis, Bogotá, Temis, pp. 10.

Rodríguez Mendoza, Fernando (2004). Procedimiento Arbitral, Editorial El País, Santa Cruz-Bolivia.

Rodríguez Mendoza, Fernando (2008). El Procedimiento Arbitral, ponencia preparada para el Primer Ciclo de Conferencias de Arbitraje Comercial, organizado por la CAINCO y la UPSA.

Salazar Paredes, Fernando (2004). Derecho Internacional Privado Boliviano, Editores Plural/CERID, La Paz-Bolivia, pp.546

Sanín Escobar, Laura. (2012). Cambios, novedades y disposiciones relevantes en el nuevo estatuto de arbitraje nacional e internacional, ley 1563 de 2012. Universidad EAFIT, Facultad de Derecho. Medellín.

Semanario Judicial de la Federación, Quinta Época, Tercera Sala, Tomo XXXVIII, pp.800

Thomson \& Aranzadi. (2004). El arbitraje en el Derecho español. Barcelona. Vidal Ramírez, Fernando, www.amcham.org.pe

Video. Mesa redonda sobre el estatuto de Arbitraje. (Antonio Pabón \& Carlos Mayorca \& Henry Sanabria). www.pablomendietapazs.blogspot.com 